\title{
Identification of alkane hydroxylase genes in Rhodococcus sp. strain TMP2 that degrades a branched alkane
}

\author{
Daisuke Takei · Kenji Washio · \\ Masaaki Morikawa
}

Received: 5 February 2008/Revised: 10 March 2008/Accepted: 12 March 2008/Published online: 15 April 2008

(C) Springer Science+Business Media B.V. 2008

\begin{abstract}
Rhodococcus sp. TMP2 is an alkanedegrading strain that can grow with a branched alkane as a sole carbon source. TMP2 degrades considerable amounts of pristane at $20^{\circ} \mathrm{C}$ but not at $30^{\circ} \mathrm{C}$. In order to gain insights into microbial alkane degradation, we characterized one of the key enzymes for alkane degradation. TMP2 contains at least five genes for membrane-bound, non-heme iron, alkane hydroxylase, known as AlkB (alkB1-5). Phylogenetical analysis using bacterial alkB genes indicates that TMP2 is a close relative of the alkane-degrading bacteria, such as Rhodococcus erythropolis NRRL B16531 and Q15. RT-PCR analysis showed that expressions of the genes for AlkB1 and AlkB2 were apparently induced by the addition of pristane at a low temperature. The results suggest that TMP2 recruits certain alkane hydroxylase systems to utilize a branched alkane under low temperature conditions.
\end{abstract}

Keywords Alkane $\cdot \operatorname{alkB} \cdot$ Biodegradation · Pristane $\cdot$ Rhodococcus sp. TMP2

Electronic supplementary material The online version of this article (doi:10.1007/s10529-008-9710-9) contains supplementary material, which is available to authorized users.

D. Takei $\cdot$ K. Washio $\cdot$ M. Morikawa $(\bowtie)$

Division of Biosphere Science, Graduate School of

Environmental Science, Hokkaido University,

Sapporo 060-0810, Japan

e-mail: morikawa@ees.hokudai.ac.jp

\section{Introduction}

Alkanes are highly reduced compounds with various structures, including short and long-chain, branched, cyclic or aromatic forms. These compounds are highly abundant in nature due to their less volatile and insoluble properties. Although many bacteria are known to metabolize various types of alkanes through distinct processes (van Beilen and Funhoff 2005), the key step for alkane degradation is recognized to be the oxygenation at a terminal methyl group (Rehm and Reiff 1981). For example, linear medium- and long-chain alkanes are oxidized by alkane monooxygenase (AlkB) or cytochrome P450s (van Beilen and Funhoff 2007). In general, alkane-degrading bacteria contain multiple genes for alkane hydroxylase and are capable of utilizing versatile alkanes (van Beilen et al. 2002). These observations suggest distinct roles of each member of the enzymes; however, detailed catalyses of alkane hydroxylase have been less well characterized.

We had previously isolated an alkane-degrading bacterium, Rhodococcus sp. TMP2, which grew on a minimum-agar plate overlaid with 2, 6, 10, 14tetramethylpentadecane (pristane) as a sole carbon source (Kunihiro et al. 2005). TMP2 has an optimum growth temperature of $30^{\circ} \mathrm{C}$ and degrades comparable amounts of $n$-alkanes (C9-C24) at temperatures ranging from 10 to $30^{\circ} \mathrm{C}$. The degradation rate of pristane by TMP 2 is high at $20^{\circ} \mathrm{C}$, but no degradation is observed at $30^{\circ} \mathrm{C}$. These observations suggest that 
diverse metabolisms for alkane degradation may be taking place in TMP2 cells grown at different temperatures.

We found decreased rates of pristane degradation when equal amounts of $n$-alkane and pristane were added to the incubation of TMP2 (Kunihiro et al. 2005). This observation suggests that degradation pathways for $n$-alkane and pristane may be identical or partially overlapped. In order to shed light on pristane degradation by TMP2, the organization and expression of the genes for alkane hydroxylase in TMP2 were investigated.

\section{Materials and methods}

Bacterial strains and culture conditions

Strain TMP2 was previously isolated from the soil of a rice field in Japan (Kunihiro et al. 2005). It was grown in Luria broth (LB; $1 \%$ bactotryptone, $0.5 \%$ yeast extract, $0.5 \% \mathrm{NaCl}$ ) or minimum salt medium BM2 (Kunihiro et al. 2005). Escherichia coli DH5 $\alpha$ was used as a host strain for the general cloning of DNA fragments. Cloning vectors pBluescript II SK ${ }^{+}$ (Stratagene, La Jolla, CA) and pGEM-T EASY (Promega, Madison, WI) were used in E. coli DH5 $\alpha$.

Alkane degradation test

Overnight cultures of TMP2 (LB, $\left.30^{\circ} \mathrm{C}\right)$ were collected by centrifugation $(12,000 \times \mathrm{g}, 5 \mathrm{~min})$ and washed twice with BM2. Culture suspension was adjusted at $\mathrm{OD}_{600}=5$ in $10 \mathrm{ml}$ of BM2. After being supplemented with various carbon sources $(0.1 \%)$, the cells were incubated at 20 or $30^{\circ} \mathrm{C}$ with shaking at $120 \mathrm{rpm}$. The remaining hydrocarbons were extracted with $10 \mathrm{ml}$ hexane/acetone $(1: 1, \mathrm{v} / \mathrm{v})$ at $12 \mathrm{~h}$ intervals. Each sample included $20 \mathrm{ppm}(\mathrm{w} / \mathrm{v})$ biphenyl as an internal standard. The amount of each hydrocarbon was quantified by the GC equipped with a nonpolar capillary column HP-1 (Hewlett-Packard), as described previously (Kunihiro et al. 2005). Each data was the average of triplicate experiments.

Identification of TMP2 alkB genes

Chromosomal DNA of TMP2 was isolated by a general phenol/SDS method (Sambrook and Russell
2001). PCRs were carried out in $50 \mu \mathrm{l}$ with KOD plus DNA polymerase (Toyobo, Osaka, Japan) and a primer set based on bacterial alkB gene sequences (see Supplementary Table 1). The PCR programme was $5 \mathrm{~min}$ at $95^{\circ} \mathrm{C} ; 30$ cycles of $1 \mathrm{~min}$ at $95^{\circ} \mathrm{C}, 1 \mathrm{~min}$ at $60^{\circ} \mathrm{C}, 2 \mathrm{~min}$ at $68^{\circ} \mathrm{C} ; 5 \mathrm{~min}$ at $68^{\circ} \mathrm{C}$ and $4^{\circ} \mathrm{C}$ until further use. PCR products were gel-purified using the QIAquick Gel Extraction Kit (Qiagen, Hilden, Germany) and cloned into pGEM-T EASY. Nucleotide sequences of the PCR fragments were determined by BigDye terminator cycle sequencing on an ABI sequencer according to the manufacturer's instructions (Perkin-Elmer Applied Biosystems, Wellesley, MA). Sequence data have been submitted into the nucleotide database under the accession numbers AB377307 (alkB1), AB377308 (alkB2), AB377309 (alkB3), AB377310 (alkB4) and AB377311 (alkB5), respectively. Distance trees based on multiple sequence alignments were generated with ClustalX (version 2.0; Thompson et al. 1997), using the neighbor-joining method with 1000 bootstrap trials.

Reverse transcriptase (RT) PCR analysis

Total RNA was isolated from bacterial cultures using RNAeasy Mini Kit (Qiagen). cDNA was synthesized from $1 \mu \mathrm{g}$ DNase-treated RNA in $20 \mu \mathrm{l}$, using random-primed reverse transcription (Reverse Transcription System, Promega, Madison, WI). One $\mu$ l of RT products was amplified in $30 \mu \mathrm{l}$ using KOD Plus DNA polymerase (Toyobo) and a primer set for each cDNA (Supplementary Table 1). The PCR condition was $2 \mathrm{~min}$ at $94^{\circ} \mathrm{C} ; 30$ cycles of $15 \mathrm{~s}$ at $94^{\circ} \mathrm{C}, 30 \mathrm{~s}$ at $60^{\circ} \mathrm{C}$ and $30 \mathrm{~s}$ at $68^{\circ} \mathrm{C} ; 2 \mathrm{~min}$ at $68^{\circ} \mathrm{C}$. The PCR products were run on $2 \%$ agarose gel in $1 \times \mathrm{TBE}$ ( $89 \mathrm{mM}$ Tris-borate, $2 \mathrm{mM}$ EDTA) and visualized by ethidium bromide staining. As an internal control to normalize the amount of templates, 16S rRNA was used. The linearity between the amount of templates and intensity of signals was verified by comparison at different cycle numbers of PCR.

Scanning electron microscopy (SEM)

TMP2 cells, grown at 20 or $30^{\circ} \mathrm{C}$ (BM2, 24 h) with hexadecane or pristine, were stepwise fixed with $5 \%$ $(\mathrm{w} / \mathrm{v}) \mathrm{OsO}_{4}$ and $2 \%(\mathrm{v} / \mathrm{v})$ glutaraldehyde in $0.1 \mathrm{M}$ phosphate-buffered saline ( $\mathrm{pH}$ 7.0). After fixation, the samples were absolutely dehydrated by increasing 
concentrations of ethanol and gold-coated in a deep vacuum. The samples were examined with a Model S-2400 (Hitachi, Japan) scanning electron microscope.

\section{Results and discussion}

\section{Alkane consumption by TMP2}

Previous work has shown that TMP2 grows better at $30^{\circ} \mathrm{C}$ than at 10 or $20^{\circ} \mathrm{C}$, whereas this strain effectively degrades pristine only at low temperatures (Kunihiro et al. 2005). To assess alkane degradation by TMP2 further, we inoculated equal amounts of overnight culture cells $\left(\mathrm{OD}_{600}=5\right)$ and evaluated their abilities to degrade different alkanes (Fig. 1). During the first day, TMP2 assimilated up to $80 \% n$ alkane (hexadecane) at both temperatures. TMP2 preferentially metabolized pristane at $20^{\circ} \mathrm{C}$ and also degraded it at $30^{\circ} \mathrm{C}$ during longer incubation times. Only a small decrease in a cyclic alkane (decylcyclohexane) could be observed with relatively higher rates at $20^{\circ} \mathrm{C}$. From these results, it is obvious that TMP2 is capable of degrading three tested alkanes, whereas each extent of degradation is various and influenced by temperatures.

Identification of $a l k B$ genes

Major intermetabolites of pristane are monoic acids in Rhodococcus strains (Nakajima et al. 1985; Sharma and Pant 2000). This implies the involvement of monoterminal oxidation pathways for pristane consumption. One of the bacterial pathways that initiates the aerobic metabolism of alkanes is a three-
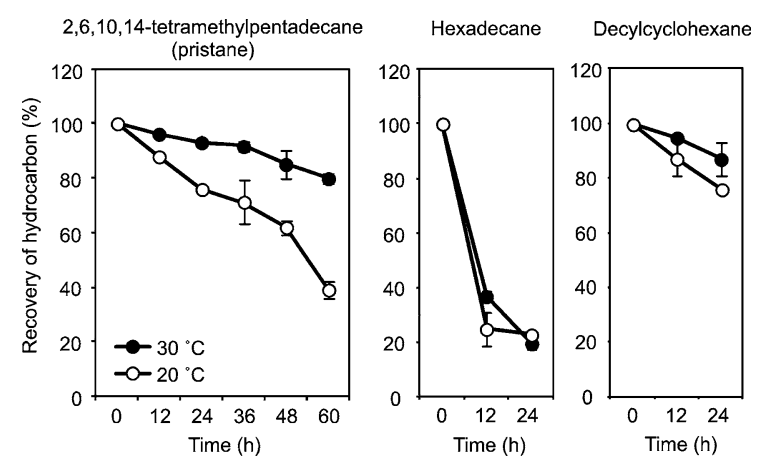

Fig. 1 Alkane consumption rates by Rhodococcus sp. TMP2, grown at 20 or $30^{\circ} \mathrm{C}$ component alkane hydroxylase system, which contains a membrane-bound alkane hydroxylase AlkB, and two soluble electron transfer components (rubredoxin and rubredoxin reductase). Several alkanedegrading strains contain multiple genes for AlkB, which are proposed to act on overlapping substrate recognitions (van Beilen and Funhoff 2007). We designed highly degenerate primers for the $a l k B$ genes and used these for PCR amplification (Supplementary Table 1). Sequence analysis of the PCR products showed that the predicted amino acid sequences were classified into five members, all of which possessed signatures specific to AlkB (Hist-1, Hist-2, HYF and Hist-3 motives). We designed five genes as alkB1 to alkB5 in TMP2 (Fig. 2).

In a phylogenetical analysis, alkB1-4 from TMP2 represents the closest homologies to the corresponding member of $R$. erythropolis NRRL B-16531 and Q15 (Whyte et al. 2002) and also exhibited higher similarities to those of Nocardia sp. H17-1, which is an oil-degrading bacterium isolated from oil-contaminated soil (Baek et al. 2006). The alkB5 gene is a novel member that locates at the deep position of the alkB4 branch. In the past studies, the presence of a fifth member of rhodococcal alkB genes has been suspected by the cross-hybridization with the DNA probes for $R$. fascians $115-\mathrm{H}$ alkB115 and $R$. fascians 154-S alkB154, but its gene has not yet been cloned (van Beilen et al. 2002). Database searches predicted higher similarities with two uncultured bacteria and Brevundimonas sp. alkB-like genes, whereas those with alkB115 and alkB154 were relatively low. The survey in our bacterial collections indicated the presence of a homologous alkB5 gene in another alkane-degrading Rhodococcus sp. T12 (Kunihiro et al. 2005). These results indicate that TMP2 has at least five different $a l k B$ homologues and alkB5 may be general in Rhodococcus spp.

Expression patterns of TMP2 alkB genes

To examine further how five $a l k B$ genes are regulated in TMP2 cells, RT-PCR analysis was used to compare their transcript levels during the incubation with alkanes (Fig. 3). The alkB3, alkB4, and alkB5 transcripts were present at constant levels in cells grown in the minimum salt medium containing $0.1 \%$ hexadecane at 20 and $30^{\circ} \mathrm{C}$. Transcript levels of alkB1 and alkB2 rose slightly after the onset of 
Fig. 2 Comparison of amino acid sequences among alkane hydroxylases in Rhodococcus sp. TMP2, and a phylogenetical relationship among bacterial alkB genes. (a) Amino acid sequence alignment comparing the predicted AlkB proteins of TMP2. Identical residues conserved in all AlkBs are highlighted in black. The three conserved histidine boxes are indicated above. (b) Phylogenetical tree among the nucleotide sequences of bacterial alkB genes. Each sequence is denoted by the strain, the gene name and the database accession number. Scale bar, 0.05 substitution per nucleotide site (a) $a l k B 1$ alkB2 alkB3 alkB4 alkB5

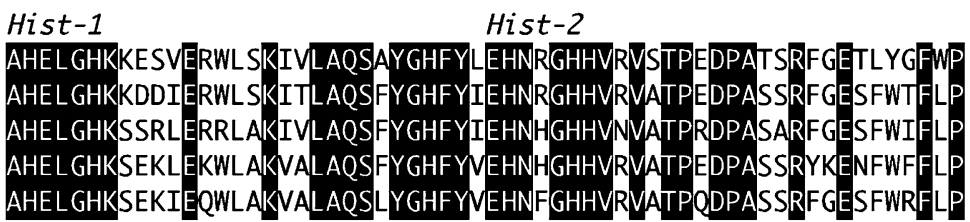
60 60 60 60 60

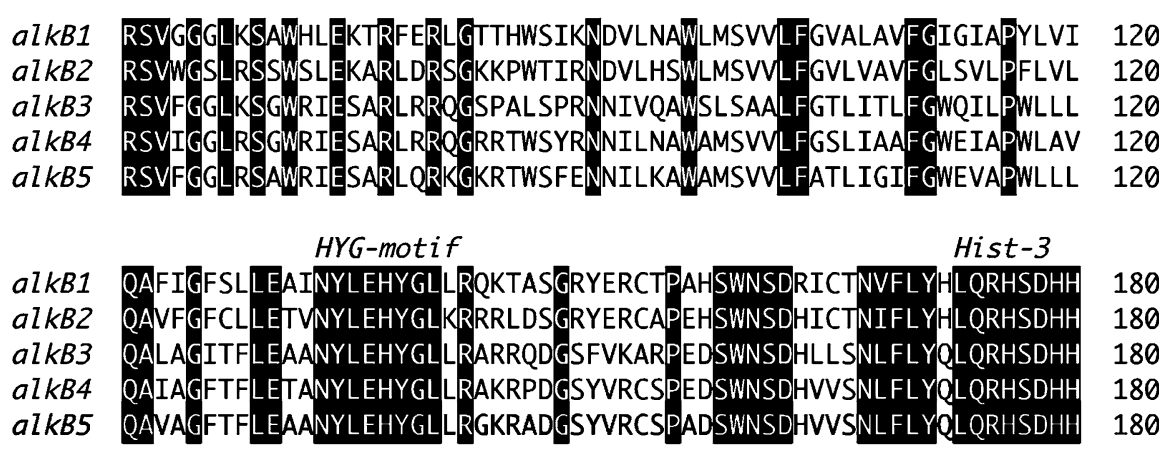

(b)

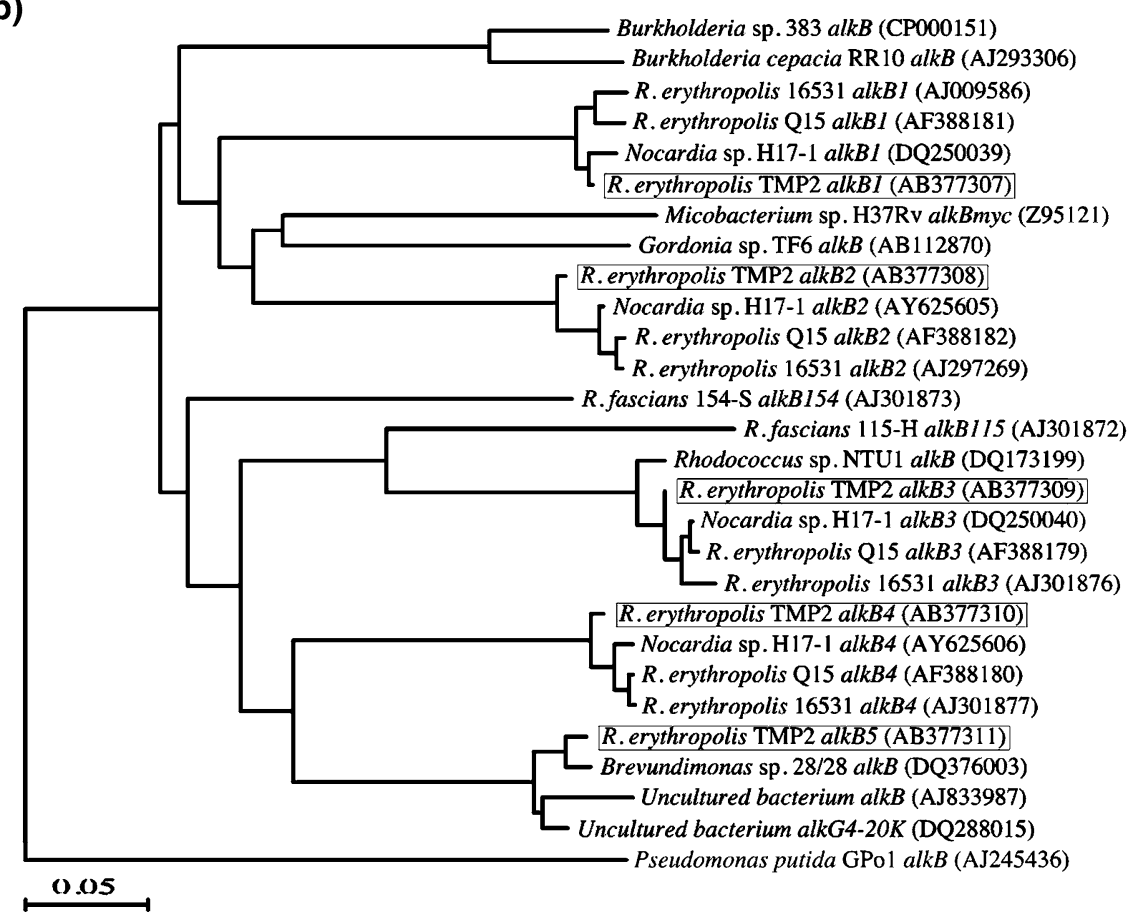

incubation with hexadecane, especially at $20^{\circ} \mathrm{C}$, and declined in the later stages of incubation. When cells were grown in the medium containing pristane, transcript levels of alkB3, alkB4, and alkB5 were also constitutive at both temperatures, whereas those of alkB1 and alkB2 increased more rapidly and significantly at $20^{\circ} \mathrm{C}$ than they did at $30^{\circ} \mathrm{C}$. Taken together, the results of this study demonstrate that the
alkB3-5 genes express constitutively, whereas expressions of alkB1 and alkB2 should be controlled by growth conditions. Temporal appearances of alkB1 and alkB2 transcripts seem to be linked with higher degradation rates of pristane as seen in Fig. 1, implying that effective alkane degradations are attributed to the induction of alkB1 and alkB2 genes in TMP2 cells. 


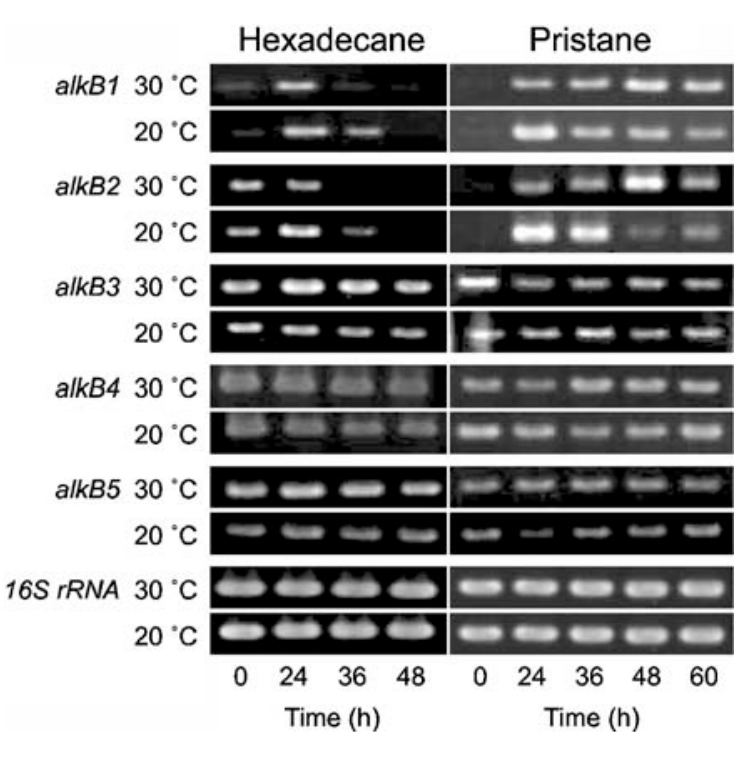

Fig. 3 Transcript levels of five alkB genes in Rhodococcus sp. TMP2 during the incubation with $0.1 \%(\mathrm{v} / \mathrm{v})$ alkanes (hexadecane, pristane) at 20 or $30^{\circ} \mathrm{C}$

Previous analysis of the alkane hydroxylase system in Pseudomonas putida GPo1 revealed that its three components are not present in equal ratios in the cells and alkane hydroxylases might share a limiting number of electron transfer components (Staijien et al. 2000). Whyte et al. (2002) reported that similar organizations of alkB1 and alkB2 genes in $R$. erythropolis NRRL B-16531 and Q15 constitute an operon-like structure including the genes for electron transfer components, whereas other members are located separately. At this stage, organizations of alkB genes in TMP2 are elusive. If alkB1 and alkB2 genes of TMP2 are co-transcribed with other component genes, as was the case for NRRL B-16531 and Q15, encoded electron transfer components might be shared by other standalone types of AlkBs (AlkB3-5) and be capable of contributing to overall elevations of the catalysis for alkane degradation. In this context, it is plausible that the transcript levels of alkBl and alkB2 are stimulated in response to the addition of alkanes (Fig. 3).

\section{SEM of TMP2 cells}

In this study, we had noticed that TMP2 cells grew into flocs with relatively dispersal and culture turbidities were high at $20^{\circ} \mathrm{C}$, whereas cells grown at $30^{\circ} \mathrm{C}$ were highly aggregated in spite of the
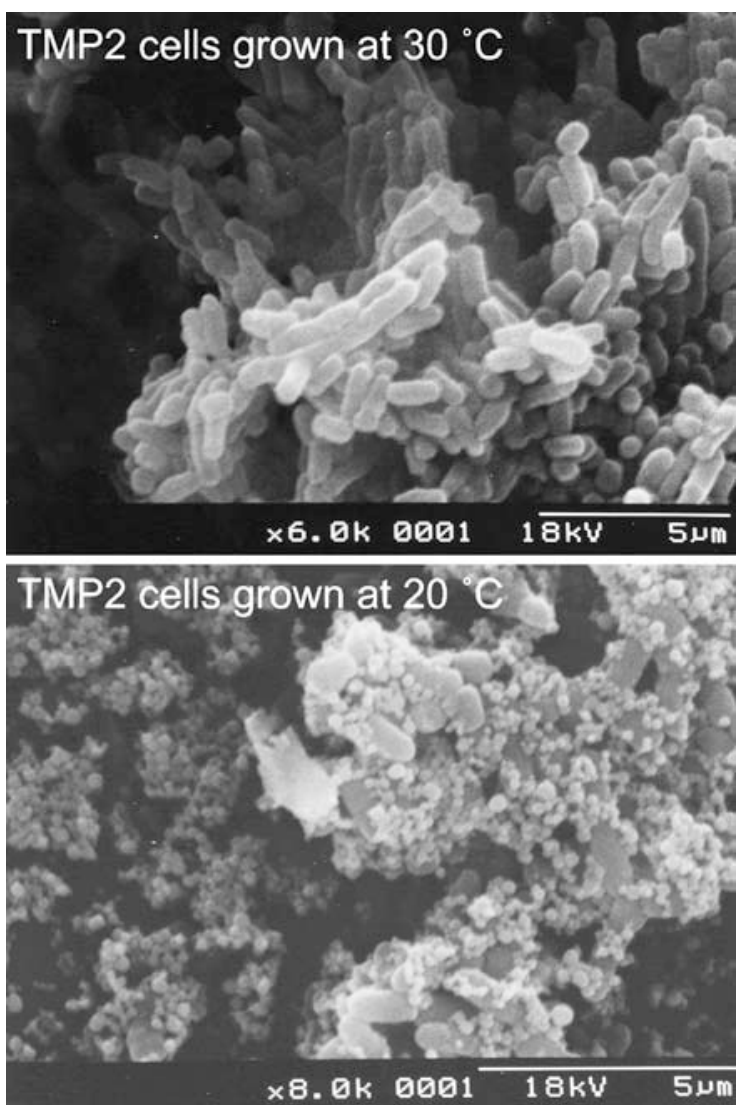

Fig. 4 Scanning electron microscope (SEM) photographs of Rhodococcus sp. TMP2 cells grown at 20 or $30^{\circ} \mathrm{C}$ with $0.1 \%$ $(\mathrm{v} / \mathrm{v})$ pristane $(\mathrm{BM} 2,24 \mathrm{~h})$

presence of hexadecane or pristane (data not shown). SEM observation revealed that the surfaces of cell flocks were smooth at $30^{\circ} \mathrm{C}$, but those seen at $20^{\circ} \mathrm{C}$ were rough and surrounded by many capsular compounds (Fig. 4). These observations indicate that drastic changes of the cell surface structure might be occurring at low temperatures.

It should be noted that Rhodococcus strains change cell surface properties in response to growth conditions, aiming to take up and assimilate hydrophobic compounds (Sanin et al. 2003; Whyte et al. 1999). Biosurfactant production is one of the strategies to metabolize hydrophobic compounds (Lang and Philp 1998; Rapp and Gabriel-Jürgens 2003). Rhodococcus sp. NCIM 5126 changes the composition of cellular fatty acids in response to the supplied hydrocarbons so that the increased lipophilicity may facilitate the uptake and import of hydrocarbons (Sharma and Pant 2000). SEM reveals that the NCIM 5126 cells are 
smooth rod-shaped and grow separately: this is different from TMP2. Because TMP2 is not a biosurfactant producer (Kunihiro et al. 2005) and branched alkane is a more hydrophobic than linear alkane, direct contact with the cell surface and hydrocarbons is important for effective assimilations. The addition of pristane at low temperatures should trigger a major change of surface properties of TMP2 cells where recruitments of certain alkane hydroxylase systems might be anticipated.

Acknowledgements This work was supported by New Energy and Industrial Technology Development Organization (NEDO), Institute for Fermentation, Osaka (IFO), and a Grantin-Aid for Scientific Research from Japan Society for the Promotion of Science (JSPS) to MM.

\section{References}

Baek KH, Yoon BD, Lee IS, Oh HM, Kim HS (2006) Biodegradation of aliphatic aromatic hydrocarbons by Nocardia sp. H17-1. Geomicrobiol J 23:253-259

Kunihiro N, Haruki M, Takano K, Morikawa M, Kanaya S (2005) Isolation and characterization of Rhodococcus sp. strains TMP2 and T12 that degrade 2,6,10,14-tetramethylpentadecane (pristane) at moderately low temperatures. J Biotechnol 115:129-136

Lang S, Philp JC (1998) Surface-active lipids in rhodococci. Antonie Van Leeuwenhoek 74:59-70

Nakajima K, Sato A, Takahara Y, Iida T (1985) Microbial oxidation of isoprenoid alkanes, phytane, norpristane and farnesane. Agric Biol Chem 49:1993-2002

Rapp P, Gabriel-Jürgens LH (2003) Degradation of alkanes and highly chlorinated benzenes, and production of biosurfactants, by a psychrophilic Rhodococcus sp. and genetic characterization of its chlorobenzene dioxygenase. Microbiology 149:2879-2890
Rehm H, Reiff I (1981) Mechanism and occurrence of microbial oxidation of long chain alkanes. Adv Biochem Eng 19:175-215

Sambrook J, Russell DW (2001) Molecular cloning: a laboratory manual, 3rd edn. Cold Spring Harbor Laboratory Press, Cold Spring Harbor, NY

Sanin SL, Sanin FD, Bryers JD (2003) Effect of starvation on adhesive properties of xenobiotic degrading bacteria. Process Biochem 38:909-914

Sharma SL, Pant A (2000) Biodegradation and conversion of alkanes and crude oil by a marine Rhodococcus sp. Biodegradation 11:289-294

Staijien IE, van Beilen JB, Witholt B (2000) Expression, stability and performance of the three-component alkane mono-oxygenase of Pseudomonas oleovorans in Escherichia coli. Eur J Biochem 267:1957-1965

Thompson JD, Gibson TJ, Plewniak F, Jeanmougin F, Higgins DG (1997) The ClustalX windows interface: flexible strategies for multiple sequence alignment aided by quality analysis tools. Nucleic Acids Res 24:4876-4882

van Beilen JB, Funhoff EG (2005) Expanding the alkane oxygenase toolbox: new enzymes and applications. Curr Opin Biotechnol 16:308-314

van Beilen JB, Funhoff EG (2007) Alkane hydroxylases involved in microbial alkane degradation. Appl Microbiol Biotechnol 74:13-21

van Beilen LB, Smits TH, Whyte LG, Schorcht S, Rothlisberger M, Plaggemeier T, Engesser KH, Witholt B (2002) Alkane hydroxylase homologues in Gram-positive strains. Environ Microbiol 4:676-682

Whyte LG, Slagman SJ, Pietrantonio F, Bourbonniere L, Koval SF, Lawrence JR, Inniss WE, Greer CW (1999) Physiological adaptations involved in alkane assimilation at a low temperature by Rhodococcus sp. strain Q15. Appl Environ Microbiol 65:2961-2968

Whyte LG, Smits TH, Labbe D, Witholt B, Greer CW, van Beilen JB (2002) Gene cloning and characterization of multiple alkane hydroxylase systems in Rhodococcus strains Q15 and NRRL B-16531. Appl Environ Microbiol 68:5933-5942 